\title{
DEGRADAÇÃO AMBIENTAL E A DIVERSIDADE BIOLÓGICA/BIODIVERSIDADE: UMA REVISÃO INTEGRATIVA
}

\author{
Antônio Pereira Júnior ${ }^{1}$; Emmanuelle Rodrigues Pereira ${ }^{2}$ \\ ${ }^{1}$ Mestre em Ciências Ambientais. Universidade do Estado do Pará \\ E-mail: antonio.junior@uepa.br \\ ${ }^{2}$ Administradora com habilitação em comércio exterior, especialista em Logística \\ Empresarial e especialista em Comércio Exterior e Negócios Internacionais.
}

Recebido em: 02/10/2017 - Aprovado em: 21/11/2017 - Publicado em: 05/12/2017

DOI: 10.18677/EnciBio_2017B79

\begin{abstract}
RESUMO
A degradação ambiental apresenta uma ligação direta com a perda da diversidade biológica ou biodiversidade em função do uso dos recursos naturais, o que compromete a conservação e manutenção dessa diversidade. O objetivo dessa pesquisa foi a realização de uma revisão integrativa para analisar os estudos relacionados com a degradação ambiental e a conservação da biodiversidade. $O$ levantamento dos dados documentais foi efetuado em artigos nacionais, internacionais, indexados, com recorte temporal compreendido entre 2008 a 2017, com especial atenção ao período entre 2013 e 2017. As bases de dados consultadas foram o Scientific Eletronic Library Online (SCIELO), Ministério do Meio Ambiente (MMA); European Environmental Agency. Foram selecionadas 32 literaturas a partir de dois indicadores da cienciometria (frequência de artigos e citações, base de dados indexados), além, do autor, ano da publicação, e a existência do devido registro (ISBN/ISSN/DOI). Os dados obtidos indicaram que a degradação ambiental está atrelada a ocorrência de impactos de origem antrópica, independente do uso do solo bem como dos recursos naturais. Quanto à diversidade biológica, a análise da literatura selecionada indicou que não há uma consonância entre os autores, ou seja, as razões da existência, ocorrência, habitat e manutenção do mesmo, ainda não são uniformes, além disso, a conservação, o uso dos recursos naturais e a proliferação da biodiversidade, não são integrados de forma a garantir que o uso desses recursos não comprometa a conservação e a manutenção da diversidade biológica. Com isso, é necessário que tal uso seja realizado sem comprometer o processo produtivo, mas que haja uma garantia quanto a manutenção da qualidade ambiental e, consequentemente, o equilíbrio ambiental e a manutenção da biodiversidade.
\end{abstract}

PALAVRAS-CHAVE: Desenvolvimento sustentável; equilíbrio ambiental; recursos naturais.

\section{ENVIRONMENTAL DEGRADATION AND BIOLOGICAL DIVERSITY / BIODIVERSITY: AN INTEGRATING REVIEW}

\section{ABSTRACT}

Environmental degradation has a direct link with the loss of biological diversity or biodiversity due to the use of natural resources, which compromises the conservation 
and maintenance of this diversity. The objective of this research was to carry out an integrative review to analyze the studies related to environmental degradation and the conservation of biodiversity. The collection of documentary data was carried out in national, international, indexed articles, with a temporal cut between 2008 and 2017, with special attention to the period between 2013 and 2017. The databases consulted were Scientific Electronic Library Online (SCIELO), Google Scholar, ISSUU, Ministry of the Environment (MMA) and European Environmental Agency. Were selected 32 literatures, which were analyzed according to the pre-determined descriptors. The obtained data indicated that the environmental degradation is linked to the occurrence of impacts of anthropic origin. Regarding biological diversity, the analysis of the selected literature indicated that there is no consonance between the authors, ie the reasons for existence, occurrence and maintenance are not yet uniform, in addition, habitat conservation, use of natural resources and proliferation are not integrated to ensure that the use of these resources does not compromise the maintenance of biological diversity. Therefore, it is necessary that such use be made so as not to jeopardize the productive process, but that it guarantees the maintenance of the environmental quality so that there is a condition of maintaining biodiversity.

KEYWORDS: Sustainable development; natural resources; environmental balance.

\section{INTRODUÇÃO}

O conceito de área degradada ou de paisagens degradadas pode ser compreendido como locais onde existem (ou existiram) processos causadores de danos ao meio ambiente, pelos quais se perdem ou se reduzem algumas de suas propriedades, tais como a qualidade produtiva dos recursos naturais (BRASIL, 1989). Essa degradação, na Lei n. 6.981, art. 3, inciso II, é conceituada dessa forma: é a degradação da qualidade ambiental, a alteração adversa das características do meio. Outro conceito, agora tratado como "área degradada" ou de "paisagens degradadas": são locais onde existem (ou existiram) processos causadores de danos ao meio ambiente, pelos quais se perdem ou se reduzem algumas de suas propriedades, tais como a qualidade produtiva dos recursos naturais que envolvem: a atmosfera, águas interiores, superficiais e subterrâneas, os estuários, o mar territorial, o solo, o subsolo, os elementos da biosfera, a fauna e a flora (BRASIL, $1981 ; 1989 ; 2000)$.

Para o Ministério de Meio Ambiente - MMA (2016), o principal problema ambiental é o desmatamento (67\%). As outras preocupações ambientais principais são: poluição da água (47\%); poluição do ar (36\%); aumento na geração de resíduos sólidos (28\%); desperdício de água (10\%); camada de ozônio (9\%); e mudança climática (6\%); entre outros aspectos mencionados com menor frequência.

Além desses problemas, Machado et al. (2013) e Hora et al. (2015) afirmam que, no Brasil, as atividades antrópicas decorrentes do crescimento econômico (Ex.: construção de estradas, atividades industriais e agrícolas mal planejadas, formação de pastagens), tem resultado em $10 \%$ de área degradada no país. Além disso, a supressão vegetal pode eliminar os meios de regeneração biótica.

Consequentemente ocorrerá a redução da diversidade biológica que compromete a sustentabilidade e a disponibilidade permanente dos recursos ambientais. Para Nery et al. (2013), essa perda de habitat está relacionada com a degradação ambiental, que ocorre após um distúrbio (como o fogo, desmatamento, furacões etc.), que altere as características originais de um sistema natural. Mas, o sistema pode apresentar um processo de regeneração natural com a recuperação 
da cobertura vegetal, retorno das espécies de animais e plantas e o restabelecimento de processos de ciclos naturais de matéria e energia.

No entanto, Rigueira et al. (2013), alerta que é preciso considerar que os processos ecológicos responsáveis pelo funcionamento dos ecossistemas e manutenção da biodiversidade, aspectos-chave a serem preservados, emergem da interação entre as partes destes sistemas (atributos bióticos e físicos) em diferentes escalas espaciais. Assim, percebe-se que a abordagem atualmente praticada tem um foco local inadequado para atingir o objetivo por não considerar processos ecológicos que, em grande parte, dependem e são influenciados por escalas espaciais mais amplas.

$\mathrm{Na}$ concepção de Janishevisk et al. (2015), a restauração do ecossistema em uma escala de paisagem, juntamente com a gestão sustentável de outros tipos de uso da terra, incluindo agricultura, pastagens, silvicultura, expansão e consolidação de áreas protegidas, é cada vez mais reconhecida como parte necessária de um pacote de atividades para a conservação da biodiversidade, reforça a prestação dos serviços ecossistêmicos e o desenvolvimento sustentável.

Essa ação, de acordo com a Convenção da Diversidade Biológica, art. 2, pode ser efetuada in situ, ex situ, e três grandes grupos para conservação: a clássica, com áreas de restrição de acesso e uso; a de uso sustentável e a repartição de beneficios oriundos da biodiversidade. No Brasil, o Decreto n. 2.159, promulga tal Convenção e afirma que todo o conteúdo descrito na redação original deve ser cumprido e, para reforçar ainda mais o processo de conservação da diversidade, foi promulgada a Lei n. 9.985 (BRASIL, 1998, 2000; UN, 1992).

Outra forma de conservar a biodiversidade, de acordo com o Ministério do Meio Ambiente (BRASIL, 2016), no Brasil, foi a intensificação ocorrida nos últimos 20 anos e, desde 2010, para gerar e disseminar conhecimento sobre a biodiversidade e o valor da biodiversidade através de parcerias multi-setoriais. Tais esforços incluem a criação e implementação de políticas e programas que incorporam valores sociais e da biodiversidade, além do desenvolvimento e lançamento de diversas iniciativas e políticas importantes voltadas para a produção e o consumo sustentáveis em diferentes níveis governamentais e no setor privado.

Mesmo com todos os esforços evidenciados para a conservação da biodiversidade, Grandi et al. (2014) alertam que se deve compreender que a biodiversidade ultrapassa a visão fragmentada de cada um dos eixos estruturais (espécie, genética e ecológica), pois ela não é um simples catálogo de genes, espécies ou ambientes, mas sim resultado da interação dinâmica entre estes três níveis hierárquicos. Analisando mais profundamente o conceito, nota-se que esta dinâmica evidencia as flutuações genéticas entre as espécies juntamente com as variações do meio em que vivem, ou seja, explica, de certo modo, os processos evolutivos relacionados à diversificação das espécies e dos ecossistemas.

Outra visão sobre conservação, foi escrita por Wanjui (2013). Esse pesquisador afirma que os humanos devem conservar a biodiversidade devido ao seu benefício, por exemplo, serviços e recursos biológicos que são essenciais para viver nossa vida na Terra. No entanto, também oferece benefícios espirituais e benefícios sociais.

Sobre a biodiversidade, Oliveira et al. (2008), comentam que as áreas ricas em biodiversidade, principalmente em espécies endêmicas e que, possuem um alto grau de degradação ambiental, foram conceituadas como sendo um Hotspots de biodiversidade. Na Amazônia, um estudo pioneiro nesse tema, o Primeiro Relatório Nacional para a Conservação da Biodiversidade (MMA, 1998), afirma que a imensa 
diversidade biológica brasileira se manifesta já na extraordinária riqueza de ecossistemas, definidas em treze unidades fitogeográficas. Para auxiliar na proteção dessa diversidade, foram criadas as áreas de Reserva Legal (BRASIL, 2012) que devem promover a conservação da biodiversidade.

Em função da riqueza de ecossistemas, Martins e Oliveira (2013), argumentam que o Brasil é considerado o país com maior diversidade de vida existente, contando com sete biomas, dentre eles Amazônia, Mata Atlântica, Pantanal e Cerrado, que apresentam formas peculiares de fauna e flora contribuindo para a riqueza de espécies do país

Outra razão para a riqueza de espécies foi escrita por Peixoto et al. (2016). Para esses autores, a grande diversidade de habitats, se traduz na riqueza de animais, plantas e fungos, doando ao bioma, o status de maior reserva de biodiversidade do planeta, estima-se, por exemplo, que a Bacia Amazônica abrigue mais de duas mil espécies de peixes de água doce, das quais, mais de 1.800 são endêmicas.

Essa diversidade, para Franco (2013) esteve em pauta como objeto de pesquisa para os cientistas e como motivo de preocupação para ativistas e cientistas. Ações para salvar espécies da extinção, sobretudo espécies mais carismáticas da fauna e da flora - como mamíferos, pássaros, árvores grandiosas ou plantas com belas flores - não são novas.

Uma visão mais ampla sobre a grande diversidade de formas de vida, de acordo com Giron (2012), é acompanhada de um grande número de diferentes relações entre elas. Tais relações são chamadas simbióticas, pois a manutenção da vida de um animal ou planta depende sempre da manutenção da vida de outro, (Simbiose significa, em grego, "viver junto"). Na natureza, a grande variedade de seres vivos, de condições de solo, de umidade, de temperatura - e até de fatores ainda não adequadamente estudados - proporciona uma enorme possibilidade de inter-relações diferentes. Quanto maior o número delas, menor a possibilidade de que todo o conjunto da natureza seja afetado por alguma interferência. É a variedade de interrelações que permite amortecer ou até neutralizar as catástrofes ou quaisquer variações bruscas no meio ambiente

Para Laurence (2010), a perda da biodiversidade tem início com a destruição do habitat ocorre quando um habitat natural, como uma floresta ou um pantanal, é alterado de forma tão dramática que não suporta mais as espécies que originalmente sustentava. As populações de plantas e animais são destruídas ou deslocadas. A destruição do habitat é considerada o principal motor de extinção de espécies em todo o mundo

O alerta quanto a essa extinção, é efetuado por Cipullo (2016). Essa autora afirma que a biodiversidade está sob pressão crescente. Os habitats disponíveis para a vida selvagem sofreram modificações dramáticas, e uma biodiversidade significativa já foi perdida nos tempos modernos. Sobre isso, Yardam et al. (2017), afirmam que o desmatamento e a degradação da terra foram reconhecidos como uma grande ameaça para o bem-estar humano e o meio ambiente devido à perda resultante de biodiversidade, degradação do solo e contribuição significativa para a emissão de gases de efeito estufa.

Outra explicação dessas perdas, de acordo com Sandifer et al. (2014), em uma conjuntura-chave na história, está ocorrendo diariamente e acelerando em face do crescimento populacional, mudanças climáticas e desenvolvimento socioeconômico desenfreado. Associa-se a esses fatos, as criações de rodovias que, segundo Graça et al. (2014), o exemplo mais visível, é a rodovia BR 319, 
abandonada desde 1988, que se mostra hoje como uma ameaça à biodiversidade e serviços ecossistêmicos da região porque o desmatamento é a principal fonte de destruição de habitats naturais e na Amazônia tem impactos severos, pois essa destruição causa extinção de espécies.

A abordagem sobre perda da biodiversidade efetuada por Alho (2012), arrola três grandes impactos negativos da ação do homem no ambiente natural:

1) Perda e alteração de hábitats e da biodiversidade.

2) Exploração predatória de recursos, e

3) Introdução de espécies exóticas nos ecossistemas.

Acrescem atualmente mais três grandes impactos negativos:

4) Aumento de patógenos.

5) Aumento de tóxicos ambientais, e

6) Mudanças climáticas.

Tudo isso envolve problemas importantes sobre a degradação da biodiversidade pela ação do homem, pela poluição, pela explosão demográfica humana associada ao uso múltiplo dos recursos naturais. Essa degradação dos recursos naturais, para Mace et al. (2014), está interligada ao conceito de fronteiras planetárias, onde todos os limites são definidos em termos das variáveis das respostas do sistema terrestre e que são relevantes para os seres humanos. Além disso, Pereira et al. (2013) afirmam que os recursos genéticos contidos nas espécies prometem desempenhar um papel crescente no desenvolvimento e, cada vez mais, nos conferem bem-estar.

Para Couto e Silva (2014), o grande problema para o sistema é que, na atualidade, o grau de utilização da natureza, e os recursos nela existentes, para a acumulação de capital, é tal que está trazendo problemas para a própria viabilização de sua acumulação, uma vez que se chega ao grau de escassez dos recursos naturais disponíveis. De acordo com Souza e Soares (2015) a condição associada a manutenção da biodiversidade e dos recursos naturais, devem assegurar o equilíbrio do clima no planeta para produção de alimentos, remédios, fornecimento da matéria prima para indústrias e na fixação de gás carbônico, entre outros. Um desenvolvimento sem a preservação não dará resultados satisfatórios e provocará o extermínio das possibilidades de vidas no planeta. $O$ desenvolvimento atual já criou passivos incalculáveis e difíceis de serem revertidos por conta do interesse do modelo capitalista que esgota os recursos naturais em nome do lucro e do bem viver para poucos.

A criação desse passivo, é confirmado por Silva et al. (2017). Esses autores escreveram que foi atingido um limite quanto aos recursos disponíveis em nível local e global e que a questão do modelo de desenvolvimento para as próximas gerações depende, entre outras coisas, dos serviços proporcionados pelo sistema natural (clima, solo, ecologia etc.). Logo, a influência antrópica nos processos globais de clima, circulação de nutrientes, deslocamento de espécies, entre outras, tem mobilizado cientistas ao redor do mundo no intuito de reconhecer e compreender que o uso que se faz dos ativos da biodiversidade está embutido no sistema socioeconômico e traz em seu bojo valores, relações sociais e políticas, direito de uso, leis, governança, mercado e relações econômicas. Por isso a importância de se estudar as relações socioecológicas integrando os componentes socioeconômicos e biofísicos

Sabe-se que o uso dos recursos naturais é antigo, pois, no estudo pioneiro efetuado em Manaus - AM, por Drummond (1996), esse autor explica que o ENCICLOPÉDIA BIOSFERA, Centro Científico Conhecer - Goiânia, v.14 n.26; p.926 2017 
extrativismo - ou uma economia extrativa - é, no sentido mais básico, uma maneira de produzir bens na qual os recursos naturais úteis são retirados diretamente da sua área de ocorrência natural, em contraste com a agricultura, o pastoreio, o comércio, o artesanato, os serviços ou a indústria. A caça, a pesca e a coleta de produtos vegetais são os três exemplos clássicos de atividades extrativas. Mas, tais atividades extrativistas necessitam de ações que permitam a conservação ou a preservação? Nesse caso, Silva (2015), escreveu que o conceito de wilderness expõe a rivalidade entre os postulados preservacionistas, que advogam o valor estético e recreativo da natureza e defendem sua proteção contra qualquer perturbação humana, e os postulados conservacionistas, que sugerem uma exploração razoável para garantir as condições materiais da existência humana.

Os conservacionistas podem proteger os ambientes com características conhecidas com alguma confiança de que as espécies de interesse permanecerão, e os restauracionistas sabem o que as espécies devem prosperar dentro de um determinado conjunto de parâmetros físicos. A troca de informações, a recuperação do biologismo de construção e a compreensão, mas os desafios para a restauração de reestruturação desaparecem.

O relato sobre conservação ambiental efetuada por Paulino e Ferreira (2016) e Sandroni e Carneiro (2016) destaca que, na década de 1990, sob os efeitos da RIO 92, as críticas ao modelo vigente àm época, se intensificaram, abrindo espaço para propostas alternativas em resposta à mobilização da sociedade brasileira e à reorientação do debate no cenário internacional que passou a dar maior ênfase à incorporação da população nos processos de conservação ambiental

Esse tipo de conservação, envolve a manutenção da existência e, de acordo com Harrison et al. (2014), está ligada a importância da biodiversidade em apoiar a prestação de serviços ecossistêmicos e os processos ecossistêmicos que os sustentam é bem reconhecida, e a nossa compreensão da natureza e o efeito possível do relacionamento entre serviços prestados pelo ecossistema e a biodiversidade.

Sobre a preservação, em especial de vegetais lenhosos, Howe (2014), afirma que as questões relativas à determinação e ao determinismo têm implicações para a preservação. Seus estudos foram analisados de forma crítica em todos os locais possíveis e as espécies diferem consideravelmente no uso de recursos, a competição entre mudas, mudas ou adultos favorece as melhores espécies adotadas.

Desta forma, a finalidade desta pesquisa foi a realização de uma revisão integrativa, alinhada a cienciometria, para analisar a produção científica sobre a degradação ambiental e a diversidade biológica, para identificar a integração entre elas quanto a conservação, uso dos recursos naturais e a manutenção da diversidade biológica/biodiversidade.

\section{MATERIAL E MÉTODOS}

Trata-se de uma pesquisa integrativa (SOUZA et al., 2009) a partir do levantamento de dados documentais, em periódicos nacionais e internacionais, indexados, com recorte temporal em dez anos (2008 e 2017) para analisar melhor a evolução da relação degradação ambiental e conservação da biodiversidade. Utilizaram-se também, estudos pioneiros, legislação brasileira pertinente, instituições nacionais e internacionais ligadas a pesquisa acerca da degradação ambiental e a diversidade biológica ou biodiversidade, em sites, com o uso de três índices cienciométricos (frequência de artigos, citações em bases indexadas, e o fator de 
impacto) associados ao acesso às publicações, facilitassem a seleção da literatura sobre degradação ambiental e biodiversidade (Scientific Eletronic Library OnLine SCIELO; Instituto Chico Mendes de Conservação da Biodiversidade - ICMBio; European Environmental Agency - EEA). Para a seleção das publicações, foram utilizados os seguintes descritores: degradação ambiental: conceitos, causas e efeitos; e diversidade biológica ou biodiversidade - conceitos, definições causas e consequências. Para a inclusão dos artigos e livros, foram determinadas e analisadas as seguintes condições: presença dos descritores, além das informações específicas sobre: autor, ano da publicação, e a existência do devido registro (ISBN/ISSN/DOI). Isso permitiu o descarte de publicações repetidas e cujo cerne da pesquisa não estivesse relacionado ao tema desse estudo.

\section{RESULTADOS E DISCUSSÃO}

\section{Seleção da literatura}

A seleção da literatura ocorreu com a aplicação de dois índices cienciométricos, além dos descritores e condições pré-definidos. Foram lidas 69 publicações, destas 32 (6 leis, 2 decretos federais e uma Resolução; 25 artigos, 16 nacionais e 9 internacionais), e 5 livros (4 nacionais e 1 internacional) preencheram os requisitos seletivos (três índices cienciométricos, descritores e informações específicas sobre autor, ano de publicação e registro oficial) o que correspondeu a 46,37\%. (Figura 1).

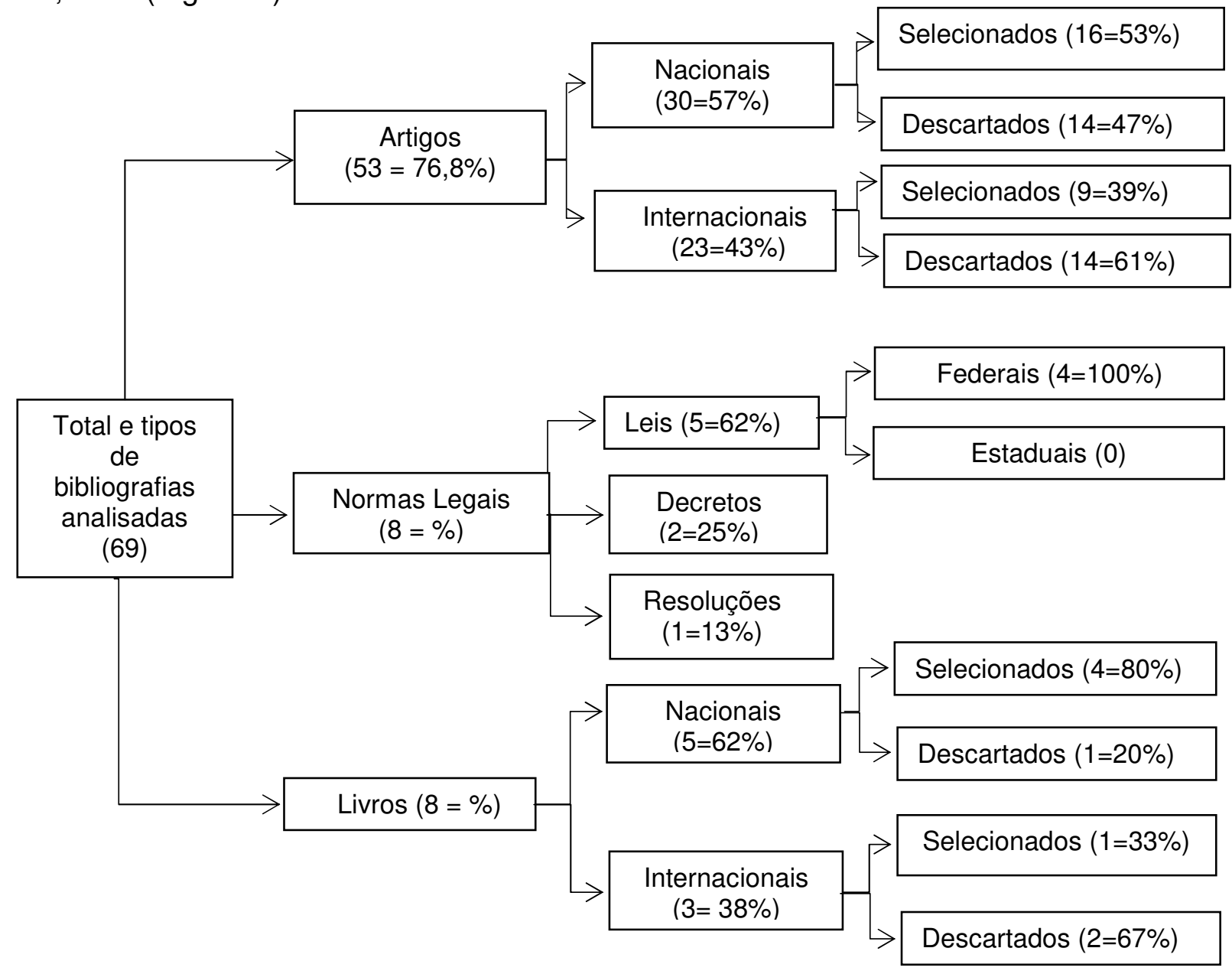

FIGURA 1 - Análise da seleção da literatura utilizada. 


\section{A DEGRADAÇÃO AMBIENTAL}

Dentre os artigos nacionais selecionados $(8=50 \%)$, os autores Alho (2012), Couto e Silva (2014), Graça (2014), Franco (2013), Hora et al. (2013), Machado et al., (2013), Martins e Oliveira (2015) e Nery et al. (2013), expõem que a degradação poderá ocorrer tanto na zona rural quanto na urbana, e ela exprime uma ação negativa provocada pelo homem, e pode advir do crescimento urbano, poluição do ar, do solo e dos rios, caça predatória, o desflorestamento, contaminação das águas, e que podem ser disseminadas para outras localidades, além da destruição dos habitats.

Outro fator da degradação é a pressão exercida sobre a floresta pela atividade madeireira, fronteira agrícola, pastagens, ou extração petrolífera (RIGUEIRA et al., 2013; KOHLRAUSCJ; JUNG, 2015; SOUZA; SOARES, 2015), mas, a natureza também se manifesta e participa dessa degradação, com ações como fogo espontâneo em florestas ou furacões, glaciações e atividades vulcânicas. Essa pressão exploratória sobre a floresta é contínua e, os dados obtidos pós seleção $(1=6,25 \%)$ indicaram que ela envolve a supressão da vegetação nativa, em especial aquelas localizadas em Áreas de Proteção Permanente (APP), além daquelas que compõem Cadastro Ambiental Rural (CAR): a Reserva Legal (RL).

Essas explorações são confirmadas por Rigueira et al. (2013), em que estes autores expõe que as áreas passíveis de uso alternativo do solo, são consideradas, neste contexto, como aquelas que não são APP ou RL. Rigueira et al. (2013) escrevem que é necessário uma avaliação criteriosa quanto as solicitações do extrativismo madeireiro, pois do contrário, corre-se o risco de extinção das espécies endêmicas ainda não estudadas cientificamente e, devido a não formação de um germoplasma, o que compromete tanto a APP quanto a RL.

$\mathrm{Na}$ análise da literatura nacional $(1=6,25 \%)$, surge um novo elemento para discussão sobre a conservação da biodiversidade: o hotspot. Nessa, visão, Oliveira et al. (2008), escreveram que ao observar, que as consequências negativas do uso dos recursos naturais pelos seres humanos continuam agravando-se, o que incrementa a necessidade e relevância pertinente à conservação, e preservação dos ecossistemas, em especial aqueles onde a agressão humana continua se agravando. Sabe-se que as perdas já ocorridas quanto aos recursos naturais como, por exemplo, árvores endêmicas, sem a devida formação de um banco de sementes, poderá alterar a configuração paisagística da flora, além de comprometer a fauna específica, ou seja, aquela que vive em co-evolução.

Os dados contidos na literatura internacional sobre destruição do habitat $(1=$ $11 \%$ ) indicaram que, no artigo escrito por Laurence (2010), globalmente, a agricultura é a maior causa de destruição do habitat. Outras atividades humanas, como a mineração, a exploração madeireira clara, a pesca de arrasto e a pesca urbana, também destroem ou degradam os habitats. Nos países em desenvolvimento, onde a maioria da perda de habitat está ocorrendo agora, os impulsionadores das mudanças ambientais mudaram fundamentalmente nas últimas décadas. Em vez de ser causada principalmente por pequenos agricultores e residentes rurais, a perda de habitat, especialmente nos trópicos, é agora substancialmente impulsionada pela globalização promovendo agricultura intensiva e outras atividades industriais.

A análise efetuada nas cinco legislações ambientais vigentes de interesse dessa pesquisa (indicou que não há uma consistência quanto a degradação ambiental enquanto impacto, todavia, as situações que são resultantes dessa ação como, por exemplo, poluição (Lei n.9.605:1988) ou o uso de fogo em práticas 
agropastoris ou florestais, danos ambientais e controle do desmatamento (Lei n.12.651:2012), são citadas nas mesmas $(2=25 \%)$. As demais (6 = $75 \%$ ) não apresentam citações sobre degradação ou, pelo menos, mecanismos ligados a degradação, o que é estranho, pois, a legislação brasileira é uma das mais severas no aspecto do controle a degradação ambiental e a conservação da biodiversidade.

Logo, as ações degradantes antrópicas ou não, agem sobre a diversidade animal e vegetal e, se o grau de intensidade for altamente impactante como, por exemplo, fragmentação ou perda de habitat, ou resiliência (no caso do solo), ou ainda a capacidade autodepuração de um corpo hídrico, certamente haverá perda de diversidade.

\section{A DIVERSIDADE BIOLÓGICA}

Nos periódicos nacionais analisados e selecionados para esse tema $(5=$ $31 \%$ ), os artigos escritos e publicados por Franco (2013), Grandi et al. (2014), Ministério do Meio Ambiente - MMA (2016), Oliveira et al. (2008) e Silva (2015), esses autores argumentaram que a diversidade biológica é a principal característica da capacidade para:

1) sobrevivência de um determinado sistema, tanto na ocorrência de uma adversidade, bem como após tal ação;

2) as questões sobre o desafio para a preservação;

3) a dependência humana;

4) a diversidade de riscos;

5) o valor, e

6) o monitoramento sistemático de habitats naturais, etc.

Outro fato citado Franco (2013), Grandi et al. (2014) e Silva (2015), foi quanto a hierarquia, pois, ela também é predominante quando se trata de biodiversidade, e as literaturas costumam citá-los. Além disso, há um conflito na dualidade homem/natureza, o que pode direcionar a proteção da biodiversidade.

Nas literaturas internacionais relacionadas com esse tema $(6=75 \%)$, os autores Harrison et al. (2014), Howe (2014), Janishevski et al. (2015), Mace (2014), Sandifer et al. (2015) e Wanjui (2013), afirmam que a biodiversidade é necessária à nossa vida, devido ao fornecido dos serviços ecossistêmicos como água limpa, madeira, fibras e alimentos, por isso, é perceptível que os serviços ecossistêmicos apresentam uma ligação estreita com a existência humana onde que ela esteja. Logo, é necessário que a conservação e manutenção do estoque dessa biodiversidade, perpasse pela restauração de áreas degradadas, de acordo com as respostas do sistema terrestre, extremamente importante ao ser humano, devido as conexões entre a natureza, a biodiversidade e o bem-estar desse ser.

\section{A CONSERVAÇÃO, USO DOS RECURSOS NATURAIS E A MANUTENÇÃO DA BIODIVERSIDADE}

A análise da literatura selecionada indicou que apenas um (6.25\%), Silva et al. (2017), escreveram que tanto a conservação, quanto a preservação da diversidade biológica garantem a sobrevivência do planeta como um todo. Permitenos a manutenção e recuperação da vida. Portanto, torna-se uma necessidade estratégica dos países detentores de tecnologias mais avançadas, resguardarem esse patrimônio, visto que mudanças climáticas globais, movimentos de continentes, erupções vulcânicas, choques de meteoros, entre outros fatores, podem alterar drasticamente a vida sobre a Terra. 
Quanto as ações sobre a tríade: conservação, uso dos recursos naturais e manutenção da biodiversidade, quatro $(4=25 \%)$, artigos foram selecionados (PEREIRA et al., 2013; PAULINO; FERREIRA, 2016; PEIXOTO et al., 2016; SANDRONI; CARNEIRO, 2016), Neles, os autores indicaram, como uma das ações para a manutenção dessa tríade, a conservação de áreas cujas paisagens já foram modificadas pelo homem, seja pelo uso agrícola, seja pastagem, ou a urbanização porque essas ações antrópicas são modificadoras da paisagem natural.

Tal afirmativa, atualmente, está acoplada a:

1) Criação de Unidades de Conservação - UCs.

2) Áreas de Proteção Permanente - APP's.

3) As Reservas Legais - RL.

4) Terras Indígenas - Tls.

Outra indicação após a análise da literatura nacional $(2=12,5 \%)$ observação positiva sobre áreas de proteção, é relatada por Giron (2012), e está associada as Áreas de Proteção Ambiental - APA, se encontram no grupo das Unidades de Conservação de Uso Sustentável, art. 14, inciso I, Lei n, 9.985:2000, e se caracteriza por ser uma área em geral extensa, dotada de atributos abióticos, bióticos, estéticos ou culturais especialmente importantes para a qualidade de vida e o bem-estar das populações humanas, e tem como objetivos básicos proteger a diversidade biológica, disciplinar o processo de ocupação e assegurar a sustentabilidade do uso dos recursos naturais(art. 15 da mesma Lei), podendo ser estabelecidas normas e restrições para sua utilização em propriedade privada. De acordo com Nery et al. (2013), a recuperação ecológica também contribui para a melhoria e manutenção da conservação da biodiversidade.

Outra indicação pós análise da literatura $(2=12,5 \%)$ para recursos naturais diz respeito a supressão de vegetação. De acordo com Rigueira (2013), a exploração da floresta depende de autorização dos órgãos ambientais competentes, mas, é necessário que haja uma ação corretiva para tal, e isso foi relatado Grandi et al. (2014), sobre áreas de reflorestamento. Eles escreveram que essa solução para a conservação e manutenção da biodiversidade é amplamente viável. Ademais, Hora et al. (2015), escrevem que, o foco dos três temas em análise, foi direcionado para a extensão territorial e a riqueza biológica dentro dessa área, e atrelado a cultura.

Outra forma de conservação do ambiente associada a manutenção da biodiversidade, é o desenvolvimento de práticas sustentáveis que, no Brasil, já está evidente no setor da silvicultura. O Ministério do Meio Ambiente (2016) publicou, no quinto relatório nacional para a convenção sobre a diversidade biológica, que 0 Brasil está também buscando os meios para alcançar a sustentabilidade da produção agrícola, particularmente com relação à produção familiar e comunitária de pequena escala, atividades de extrativismo e produção orgânica/agroecológica, através de diversas políticas e iniciativas. Frente ao considerável tamanho do setor agrícola no país, os avanços atuais precisam ainda ganhar escala e aumentar a taxa de adoção de práticas sustentáveis.

Em relação a diversidade de passagens geográficas, a análise dos dados obtidos nas literaturas $(2=25 \%$ ), é notório que a Amazônia com, aproximadamente $5.020,000 \mathrm{~km}^{2}$, apresenta variedades de paisagens (Ex.: manguezais, campina, capinarana, savanas, etc.), logo, diversidade de habitats e de nutrientes fornecidos se constituem em dois fatores para a diversidade de populações com peculiaridades para o forrageamento, deslocamento, reprodução, genes, e outros atributos inerentes a biodiversidade. Em relação a análise da legislação brasileira, os dados 
indicaram que há citações para a preservação do ambiente e, consequentemente da biodiversidade, inclua-se aquela necessária aos reservatórios artificiais (CF, 1998, art. 225, § 1, inciso II; Brasil, 2002).

Em função do uso dos recursos naturais citados na Lei n. 6938:1981, art. 3, inciso V: atmosfera, águas interiores, superficiais e subterrâneas, estuários, mar territorial, solo e subsolo, elementos da biosfera, fauna e flora, os dados obtidos indicaram que deverá ocorrer a racionalidade e a adequação nesse uso e, no art. 4, inciso III da mesma Lei, está escrito que ambos devem ser normatizados. Todavia, o contra-argumento $(1=6.25 \%)$ dessa racionalidade é exposto por Couto e Silva (2014), quando esses autores escrevem que a simples racionalização, em função do modelo econômico vigente, não é uma sustentabilidade conservadora.

Das literaturas nacionais analisadas, apenas uma $(1=6,25 \%)$, escreveu sobre a integração entre recursos naturais e a biodiversidade. Souza e Soares (2015), afirmaram que, no Brasil o tema dos recursos naturais e da biodiversidade estão mesclados e integrados no conhecimento técnico cientifico e no conhecimento tradicional e milenar dos povos e comunidades que vivem nas ricas regiões dos ecossistemas do país. Esta interação está contemplada na Convenção sobre Diversidade Biológica que prevê a repartição justa e equitativa dos benefícios gerados pelo acesso a recursos genéticos e aos conhecimentos tradicionais. Entretanto, depois de mais de dez anos da entrada do acordo em vigor, pouquíssimo se avançou no estabelecimento de um regime internacional para balizar e regular as relações de acesso e repartição de benefícios.

A análise da literatura internacional $(2=22 \%)$ escrita por Wanjui $(2013)$ e Cipullo (2016), indicou que o uso dos recursos naturais envolvem a insustentabilidade, o consumo insustentável e a pobreza persistente em países emergentes, em consequência disso, a biodiversidade declina. Tal argumentação envolve a exploração dos recursos naturais para incrementar a produção de produtos cujo consumo é elevado (Ex.: telefones móveis), mas, a produção desses aparelhos envolve uma gama elevada de metais do subsolo, ou seja, de recursos naturais.

A degradação ambiental é fato! A perda biodiversidade também! A relação direta que ocorre entre elas, é verídica e traz consigo o uso, a exploração e a geração de novos produtos que dependem da matéria-prima ou recurso natural disponível para tal produção. A degradação ocorre no ar, água e solo, justo onde há maior ocorrência de diversidade de espécies devido a oferta de habitats e a destruição a partir da extração do insumo necessário a produção industrial.

Outro fator que está em discordância é quanto a composição do conceito sobre degradação ambiental, atualmente mais conciso entre os pesquisadores quando comparado com o da biodiversidade que, em nível nacional ainda não tem um consenso, o que já ocorre entre os pesquisadores internacionais. Mas, nacionalmente, já existem publicações que demonstram um parâmetro terminológico similar.

Finalmente, a perda da biodiversidade que é atrelada à degradação do ambiente, especialmente em função da exploração madeireira e mineral, duas riquezas predominantes na Amazônia e, em ambos os casos, a densidade populacional pode diminuir devido a perda do fluxo gênico e o desequilíbrio ambiental que comprometem o ciclo reprodutivo como, por exemplo, incremento da temperatura devido a perda do dossel, o que determina maior incidência solar em espécies sensíveis às modificações na temperatura atmosférica. 


\section{CONCLUSÕES}

A degradação ambiental está ligada de forma direta a diversidade biológica, especialmente quando a exploração dos recursos naturais envolvem 0 desflorestamento, o revolvimento do solo, a contaminação dos corpos hídricos porque o processo produtivo, principalmente o tecnológico, apresenta-se em franca expansão, e isso, em geral, tem causado grandes perdas ou fragmentações de habitats.

Essa fragmentação tem provocado diminuição na densidade populacional das espécies vegetais e animais, nestas, o processo de posto que, essas espécies sofrem migração involuntária ou até a extinção devido a perda do habitat. Nesse caso, a conservação ambiental não é evidenciada, embora a ampla gama legislativa ambiental brasileira tenha sido elabora pata essa finalidade.

O descontrole e a velocidade de exploração dos recursos naturais existentes, seja para agricultura, pecuária, mineração, elaboração de novos produtos para incrementar o avanço tecnológico, todavia, os resíduos pós produção ainda agridem de maneira violenta o meio ambiente e, especial, os corpos hídricos e, essa ação determina alterações no equilíbrio ambiental, com perda de estruturas básicas necessárias à proliferação e manutenção da biodiversidade como, por exemplo, o habitat, o nicho ecológico, logo, a integração entre eles ainda não foi alcançada, devido a permissão, por atos legais da exploração, industrialização e comercialização dos recursos naturais, dentro e fora das UCs.

Além disso, a conservação da vegetação e corpos hídricos, ainda não foi encontrada uma linha de integração entre o desenvolvimento econômico, o uso dos recursos naturais de forma a manter as gerações atuais e as futuras, mas sem comprometer tal desenvolvimento. Por enquanto, as pesquisas estão equacionando os elementos fundamentais necessários à manutenção uso dos recursos naturais $\mathrm{e}$ a manutenção da diversidade biológica, seja ela animal/vegetal/ambas.

\section{REFERÊNCIAS}

ALHO, C. J. R. Importância da biodiversidade para a saúde humana: uma perspectiva ecológica. Estudos Avançados. São Paulo, v. 26, n, 74, p. 151 - 165, set, 2012. DOI: http://dx.doi.org/10.1590/S0103-40142012000100011

BRASIL. Lei n. 6938, de 31 de agosto de 1981. Dispõe sobre a Política Nacional do Meio Ambiente, seus fins e mecanismos de formulação e aplicação, e dá outras providências. Diário Oficial [da] República Federativa do Brasil. Poder Executivo. Brasília, DF, 02 de setembro de 1981, Seção 1, p. 1.

\footnotetext{
Constituição (1988). Art. 225. TíTULO VIII, Capítulo VI - Do Meio Ambiente Inciso $\S$ 1, inciso ll. Disponível em: https://www.senado.gov.br/atividade/const/con1988/con1988_15.12.2016/art_225_.a sp.. Acesso em 07 set. 2017.
}

Decreto n. $\mathbf{9 7 . 6 3 2}$ de 10 de abril de 1989. Dispõe sobre a regulamentação do Artigo $2^{\circ}$, inciso VIII, da Lei $n^{\circ} 6.938$, de 31 de agosto de 1981, e dá outras providências. Diário Oficial [da] República Federativa do Brasil. Poder Executivo, Brasília, DF. 12 abr.1989. Seção 1, P.1.

Decreto n. 2.519 de 16 de março de 1998. Dispõe sobre a promulgação da Convenção sobre Diversidade Biológica, e dá outras providências. Diário Oficial 
[da] República Federativa do Brasil. Poder Executivo, Brasília, DF. 16 mar.1989. Seção 1, p. 1

Ministério de Meio Ambiente. Primeiro Relatório Nacional para Convenção da Biodiversidade. Brasília: MMA, 1998 Disponível em: < http://www.mma.gov.br/informma/item/7926>. Acesso em 10 out.2017

Lei n. 9.985, de 18 de julho de 2000. Regulamenta o art. 225, $\S 1^{\circ}$, incisos I, II, III e VII, da Constituição Federal, institui o Sistema Nacional de Unidades de Conservação da Natureza e dá outras providências. Diário Oficial [da] República Federativa do Brasil. Poder Executivo, Brasília, DF. 18 out,2012. Seção 1, p. 1

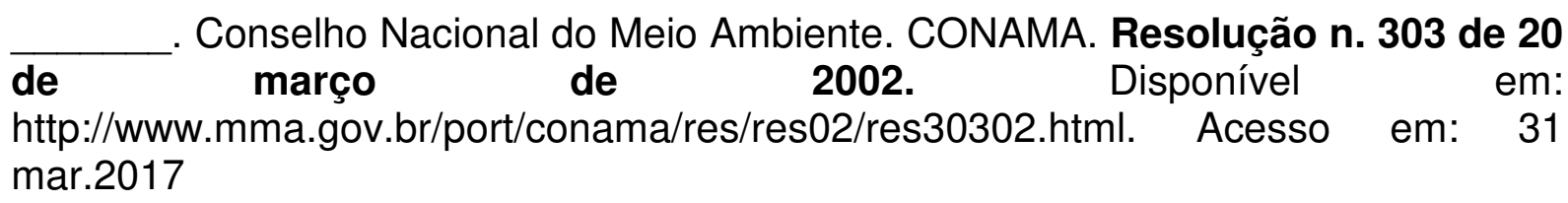

Lei n. 12.727 de 17 de outubro de 2012. Altera a Lei $n^{0} 12.651$, de 25 de maio de 2012, que dispõe sobre a proteção da vegetação nativa; altera as Leis $\mathrm{n}^{0 \mathrm{~s}} 6.938$, de 31 de agosto de 1981, 9.393, de 19 de dezembro de 1996, e 11.428, de 22 de dezembro de 2006; e revoga as Leis $n^{\text {os }} 4.771$, de 15 de setembro de 1965, e 7.754, de 14 de abril de 1989, a Medida Provisória $\mathrm{n}^{0} 2.166-67$, de 24 de agosto de 2001, o item 22 do inciso II do art. 167 da Lei $n^{\circ} 6.015$, de 31 de dezembro de 1973, e $0 \S 2^{\circ}$ do art. $4^{\circ}$ da Lei $n^{\circ} 12.651$, de 25 de maio de 2012. Diário Oficial [da] República Federativa do Brasil. Poder Executivo, Brasília, DF. 19 jul.2000. Seção 1, p. 1

Ministério do Meio Ambiente. Quinto Relatório Nacional para a Convenção da Biodiversidade. Brasília: MMA, 2016. Disponível em: < http://www.mma.gov.br/informma/item/10772-quinto-relat\%C3\%B3rio>. Acesso em 10 out. 2017

CIPULLO, N. Biodiversity Indicator's: the accounting point of view. Elsevier. Procedia Economic and Finances. v. 39, p. 539 - 544, 2016. DOI: 10.1016/S22125671(16)30297-0

COUTO, E. P.; SILVA, F. O. Desenvolvimento (in) sustentável. Enciclopédia Biosfera, Goiânia, v. 10, n. 8, p. 41 - 54, abr.2014. ISSN: 2317-2606.

DRUMMOND, J. A. A extração sustentável de produtos florestais na Amazônia Brasileira. Estudos Sociedade e Agricultura. Rio de Janeiro, n. 6, p. 115 - 137, jul. 1996. ISSN: $1413-0580$

FRANCO, J. L. A. O conceito de biodiversidade e a história da biologia da conservação: da preservação da. História. São Paulo, v. 32, n. 2, pp. 21 - 48, jul/dez, 2013. ISSN 1980-4369

GIRON, J. Diversidade biológica, relevância e contexto. In: BUTZKE, Alindo; PONTALTI, Sieli (Org). Os recursos naturais e o homem. 0 direito ao meio ambiente ecologicamente equilibrado frente à responsabilidade Solidária. 
Caxias do Sul: EDUSC, 2012. Seção IV. Cap. 17, p. 289 - 307. ISBN 978-85-7061687-6

GRAÇA, P. M. L. A. et al. Cenários de desmatamento para região de influência da rodovia BR-319: perda potencial de habitats, status de proteção e ameaça para a biodiversidade. In. EMÍLIO, T.; LUIZÃO, F. Cenários para a Amazônia: clima, biodiversidade e uso da terra. Manaus: INPA, 2014, cap. 8, p. 91 - 104. ISBN 97885-211-0126-0 CDD 551.69811

GRANDI, L. A.; CASTRO, R. G.; MOTOKANE, M. T.; KATO, D. S. Concepções de monitores e alunos sobre o conceito de biodiversidade em uma atividade de trabalho de campo. Cadernos CIEMAC. Ribeirão Preto, v. 4. n. 1, P. 1 - 17, 2014. ISSN 2178-9770.

HARRYSON, P. A. Linkages between biodiversity attributes and ecosystem services: A systematic review. Ecosystem Services. USA, n. 9, p. 191 - 203, may./2014. DOI: http://doi.org/10.1016/j.ecoser.2014.05.006

HORA, N. N.; FONSECA, M. J. C. F.; SODRÉ, M. N. R. Biodiversidade e Conservação; um olhar sobre a forma dos licenciandos de biologia. Revbea. São Paulo, n.10, n. 1. p. $56-74$, 2015. ISSN 1981-1764.

HOWE, H. P. Diversity Storage: Implications for tropical conservation and restoration. Global Ecology and Conservation. USA, n.2, p. 349 - 358, oct. 2014 DOI: http://dx.doi.org/10.1016.j.gecco.2014.10.004

JANISHEVISKI, L.; SANTAMARIA, C.; GIDDA, S. B.; COOPER, D. H.; BRACALION, P. H. S. Ecosystem restoration, protected areas, and biodiversity conservation. Unasylva. USA, v. 66. n. 245, p. 19-27, mar, 2015.

DOI 10.1080/20702620.2001.10434156.

LAURENCE, W. F. Habitat destruction: death by a thousand cuts. In: SHODI, Navjot S.; EHRLINCH, Paul R. Conservartion Biology for all. Oxford University. New York, 2010. Cap. 4, p. 76 - 83. ISBN 978-0-19-955423-2 (Hbk.)

MACE, G M. REYERS,L.; ALKEMADE, R.; BIGGS, R.; CHAPIN, S.; et al., Approach's to defining a planetary boundary for biodiversity. Global Environmental Chang e. Australia, n. 28, p. 289 - 297, jul. 2014. DOI: http://dx.doi.org/10.1016/j.gloenvcha.2014.07.009

MACHADO, C. J. S.; VILANI, R. M.; FRANCO, M. G.; LEMOS, S. D. C. Legislação ambiental e degradação ambiental do solo pela atividade petrolífera no Brasil. Desenvolvimento e Meio Ambiente, Curitiba, v. 28, p. 41 - 55, jul/dez. 2013. DOI: http://dx.doi.org/10.5380/dma.v28i0

MARTINS, C.; OLIVEIRA, H. T. Biodiversidade no contexto escolar: Concepções e práticas em uma perspectiva de Educação Ambiental crítica. Revbea. São Paulo, v.10, n. 1 , p. $127-145,2015$. ISSN 1981-1764. 
NERY, E. R. A. et al. O conceito de restauração na literatura científica e na legislação brasileira. Revista Caititu, Salvador, n. 1, p. 43 - 56, set. 2013. DOI10.7724/caititu.2013.v1.n1.d04

OliVEIRA, D. A.; PIETRAFESA, J. P.; BARBALHO, M. G. S. Manutenção Da Biodiversidade e o Hotspots Cerrado. Caminhos da Geografia. Uberlândia, v. 9. N. 26, p. 101 - 114, jun/2008. ISSN 1678-6343

PAULINO, A. F.; FERREIRA, R. L. A biodiversidade e os impactos ambientais potenciais decorrentes do novo Código Florestal Brasileiro. 2016. Disponível em: < < $\quad$ http://escolasuperior.cetesb.sp.gov.br/wpcontent/uploads/sites/60/2016/06/fabricio_alex_paulino.pdf>. Acesso em 15 jul.2017.

PEIXOTO, A. L.; LUZ, J. R. P.; BRITO, M. A. (Org.). Conhecendo a biodiversidade. Brasília: MCTIC/CNPq/PPbio, 2016, p.114. ISBN: 978-85-63100-08-5 CDD:5770981.

PEREIRA, R. C.; ROQUE, F. O.; CONSTANTINO, P. A. L SABINO, J.; UEHARAPRADO, M. Monitoramento in situ da biodiversidade. Proposta para um Sistema Brasileiro de Monitoramento da Biodiversidade. Brasília: ICMBio, 2013. ISBN 978-85-65872-04-1

RIGUEIRA, D. M. G. et al. Perda de habitat, leis ambientais e conhecimento científico: proposta de critérios para a avaliação dos pedidos de supressão vegetal. Salvador, v.1, n. p. 21 - 42, set. 2013 DOI 10.7724/caititu.2013.v1.n1.d03

SADRONI, L. T.; CARNEIRO, M. J. T. Conservação da biodiversidade nas ciências sociais brasileiras: uma revisão sistemática de 1990 a 2010. Amazônia \& Sociedade. São Paulo, v. 12, n.3, p. 21 - 46, jul/set. 2016. DOI: http://dx.doi.org/10.1590/1809-4422ASOC130181V1932016

SANDIFER, P. A.; SUTTON-GRIER, A. E.; WARD, B. P. Exploring connections among nature, biodiversity, ecosystem services, and human health and well-being: Opportunities to enhance health and biodiversity conservation. Ecosystem Services. Holanda, n. 12, p. $1-15,2015$. DOI: http://dx.doi.org./10.1016/j.ecoser.2014.12.007

SILVA, A. T. R. A conservação da biodiversidade entre os saberes da tradição e a ciência. Estudos Avençados, v.29, n.83, p. 233 - 259, 2015. DOI 101590/S013040142015000100012

SILVA, L. E.; ALQUERQUE, U. P.; AMARAL, W. Uso sustentável da biodiversidade e conservação de recursos naturais. Guaju, Matinhos, v. 3, n. 1, p. 2 - 10, jan/jun.2017 DOI: http://dx.doi.org/10.5380/guaju.v3i1.53845

SOUZA, A. C.; COLLUCI, M. Z. O.; ALEXANDRE, N. M. C. Sistemas osteomusculares da enfermagem: uma revisão integrativa; Ciência, Cuidado e Saúde. Maringá, v. 8, n. 4, p. 683 - 690, out/dez. 2009. DOI: 10.4025/cienccuidsaude.v8i4.9707 
SOUZA, M. G. V.; SOARES, E. Conservação da biodiversidade e uso dos recursos naturais. 2015. Disponível em: <https://www.kooperationbrasilien.org/de/themen/menschenrechte-gesellschaft/traditionelle-voelkergemeinschaften/leninha-und-elmy-biodiversitaet<. Acesso em 09 set. 2017.

UN. United Nations. Convention on Biological Diversity. 1992. Disponível em< http://www.cbd.int/doc/legal/cbd-en.pdf>. Acesso em: 02 set. 2017.

YARDAM, E.; TIGABU, M.; MONGE, A. Rehabitation of degraded dryland ecosystem - review. Silva Fennica, v. 51, n. 1B, p. 1 - 32, 2017. DOI: http://doi.org/10.14214/sf.1673. 